\title{
EBM-onderwijs in de praktijk: moeilijker dan gedacht
}

\section{Samenvatting}

Kortekaas MF, Bartelink ME, Zuithoff NP, Van der Heijden GJ, De Wit NJ, Hoes AW. EBM-onderwijs in de praktijk: moeilijker dan gedacht. Huisarts Wet 2017;60(11):551-3.

ACHTERGROND Training in evidence-based medicine (EBM) is een belangrijk onderdeel van de huisartsopleiding. Onderzoek laat zien dat in de klinische praktijk geïntegreerd EBM-onderwijs betere resultaten geeft dan opzichzelfstaande (stand-alone) theoretische modules. Echter, deze onderzoeken werden niet uitgevoerd binnen de huisartsgeneeskunde en keken niet naar effecten op EBM-gedrag in de praktijk na de opleiding. Wij onderzochten de effecten van geïntegreerd versus het gebruikelijke stand-alone EBM-onderwijs op EBM-gedrag, -attitude en -kennis bij huisartsen bij afronding van de opleiding en een jaar daarna.

METHODEN In een pragmatische, cluster-gerandomiseerde trial werden zes groepen derdejaars aios huisartsgeneeskunde van het UMC Utrecht verdeeld over geïntegreerd of gangbaar EBM-onderwijs. Voor EBM-gedrag keken we naar het handelen volgens NHG-richtlijnen, het hebben van klinische dilemma's en het zoeken naar antwoorden. Aios hielden consultlogboeken bij. EBMattitude en -kennis werden gemeten met behulp van gevalideerde vragenlijsten. Data werden verzameld aan het begin $\left(T_{0}\right)$ en einde $\left(T_{1}\right)$ van het derde jaar, en een jaar na afronding van de opleiding $\left(T_{2}\right)$. Multilevel-analyses werden uitgevoerd op basis van intention-to-treat.

RESULtATEN Van 82 aios in 6 groepen deden er 79 mee (96\%); 39 in de interventiegroep, 40 in de controlegroep. Van 76 (96\%) hiervan waren logboekdata op baseline $\left(T_{0}\right)$ beschikbaar, van 60 (76\%) op $T_{1}$ en van 53 (67\%) op $T_{2}$. We vonden geen significante verschillen tussen de groepen in EBM-gedrag, -kennis en attitude.

CONCLUSIE Meer in de praktijk geïntegreerd EBM-onderwijs heeft, vergeleken met het gebruikelijke, stand-alone, onderwijs, geen effect op EBM-toepassing, -attitude of -kennis van (toekomstige) huisartsen.

\section{INLEIDING}

Evidence-based medicine (EBM), dat wil zeggen 'expliciet, oordeelkundig en consciëntieus gebruikmaken van het beste beschikbare bewijs in combinatie met klinische expertise en de wensen van de patiënt bij het maken van een keuze voor de beste behandeling', is een van de hoekstenen van de moderne geneeskunde. ${ }^{1}$ In Nederland leren aios gedurende hun driejarige opleiding te werken volgens de vijf stappen van EBM: vragen, zoeken, kritisch beoordelen, toepassen en evalueren..$^{2,3}$ Hoe je dat alles het best kunt onderwijzen, is echter nog niet helemaal duidelijk. ${ }^{4}$ Huisartsopleidingen bieden vaak theoretische modules aan, maar een systematische review heeft al in 2004 laten zien dat die alleen de kennis over EBM vergroten en dat praktisch onderwijs nodig is om ook de nodige vaardigheden, attitude en gedrag aan te leren.5 Dat effect van geïn- tegreerd EBM-onderwijs is echter nog nooit in gecontroleerd onderzoek gemeten, laat staan dat gekeken is naar de effecten na het afstuderen., ${ }^{, 6}$ Bovendien is het nooit onderzocht in de huisartsenpraktijk, waar zowel de setting (één supervisor en één aios) als de patiëntenpopulatie ingrijpend verschillen van de ziekenhuisomgeving.

Wij ontwikkelden een geïntegreerd EBM-onderwijsprogramma voor aios Huisartsgeneeskunde waarin de nadruk lag op de laatste twee stappen van EBM: toepassen en evalueren. We gaven de huisartsopleiders een bijscholing waarin de nadruk lag op hun voorbeeldfunctie bij het integreren en bespreken van EBM in de praktijk.? Vervolgens vergeleken we in een RCT de effecten van dit geïntegreerde EBM-onderwijs met die van losse theoretische EBM-modules (zie [online tabel 1]).

\section{METHODE}

\section{Opzet en deelnemers}

Voor deze pragmatische, clustergerandomiseerde trial benaderden we alle 82 aios die in 2011 begonnen met het derde jaar Huisartsgeneeskunde aan de huisartsopleiding Utrecht. Wij vormden zes groepen van elk ongeveer 12 aios en wezen deze aan het begin van het studiejaar gerandomiseerd toe aan een interventiearm en een controlearm (clusterrandomisatie).

\section{Wat is bekend?}

- Huisartsen raadplegen de NHG-Standaarden vaak, maar in de praktijk lijkt er nogal wat te schorten aan hun evidence-based handelen.

- Evidence-based medicine (EBM) wordt in de huisartsopleiding onderwezen in losse, theoretische modules.

- Theoretische modules vergroten alleen kennis over EBM; in de praktijk geïntegreerd EBM-onderwijs is nodig om ook de nodige vaardigheden, attitude en gedrag aan te leren.

\section{Wat is nieuw?}

- Een geïntegreerd EBM-onderwijsprogramma in het laatste jaar van de huisartsopleiding leidt niet tot grote verbeteringen in de kennis over, aandacht voor en houding jegens EBM.

- Aios en opleiders zijn weinig geneigd zelf op zoek te gaan naar wetenschappelijke onderbouwing van hun klinisch handelen.

UMC Utrecht, Julius Centrum voor Gezondheidswetenschappen en Eerstelijnsgeneeskunde, Utrecht: dr. M.F. Kortekaas, huisarts-epidemioloog; dr. M.E.L. Bartelink, huisarts-epidemioloog; dr. N.P.A. Zuithoff, statisticus; prof.dr. N.J. de Wit, huisarts, hoogleraar Huisartsgeneeskunde; prof. dr. A.W. Hoes, epidemioloog, hoogleraar Klinische epidemiologie. AMC/VUmc, afdeling Sociale tandheelkunde, Amsterdam: prof.dr. G.J.M.G. van der Heijden, epidemioloog, hoogleraar Sociale tandheelkunde. $•$ Correspondentie: m.f.kortekaas@umcutrecht.nl • Mogelijke belangenverstrengeling: niets aangegeven.

Dit artikel is een Nederlandse bewerking van Kortekaas MF, Bartelink MEL, Zuithoff NPA, et al. Does integrated training in evidence-based medicine (EBM) in the general practice (CP) specialty training improve EBM behaviour in daily clinical practice? A cluster randomised controlled trial. BMJ Open 2016;6: eo10537. Publicatie gebeurt met toestemming. 


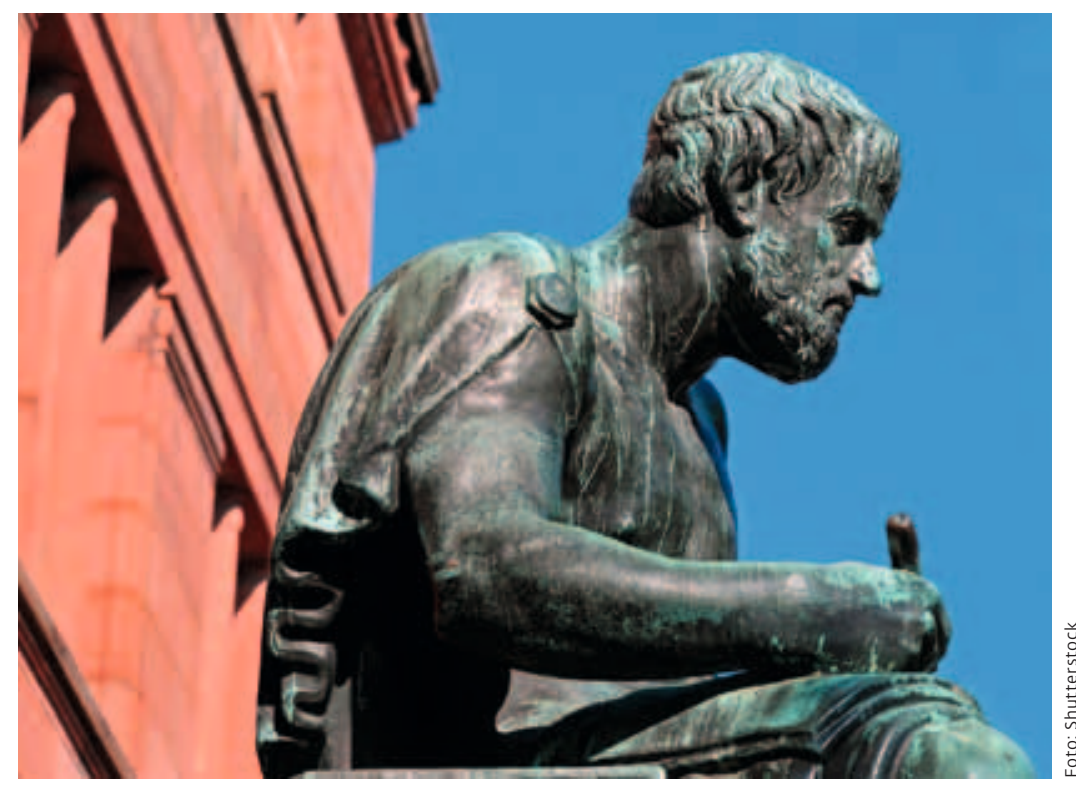

EBM draait om de integratie ervan met de eigen klinische expertise en de wensen en voorkeuren van de patiënt.

Er waren drie meetmomenten: bij aanvang van de oplei$\operatorname{ding}\left(\mathrm{T}_{\mathrm{o}}\right)$, aan het einde van de opleiding $\left(\mathrm{T}_{1}\right)$ en een jaar na het afstuderen $\left(\mathrm{T}_{2}\right)$. Als aanvangskenmerken noteerden we leeftijd, geslacht, medische opleiding, klinische ervaring en score op de Landelijke Huisartsgeneeskundige Kennistoets (LHK), ${ }^{8}$ en de score die de deelnemers gaven aan hun eigen EBM-attitude en -kennis op een vijfpunts Likert-schaal ( $1=$ erg slecht, 5 = erg goed).

De medisch-ethische commissie van UMC Utrecht achtte voor dit onderzoek geen informed consent nodig van patiënten. We vroegen de deelnemende aios om informed consent voor het gebruik van de gegevens.

\section{Interventie}

In beide onderzoeksarmen behandelden de onderwijsprogramma's de vijf essentiële EBM-stappen, maar in de interventiearm legde het geïntegreerde programma meer nadruk op de laatste twee stappen van EBM, toepassen en evalueren (zie [online tabel 1]).9,10 Het EBM-onderwijs op de terugkomdagen voor de interventiegroep pasten we zodanig aan dat de relatie tussen theorie en praktijk meer werd benadrukt. Ten slotte coachten we de huisartsopleiders zodat zij EBM beter konden integreren op de werkplek.

\section{Meetinstrumenten en metingen}

We onderzochten of de deelnemers handelden volgens richtlijnen, dat wil zeggen de kernaanbevelingen in de NHG-Standaarden volgden dan wel daar beredeneerd van afweken. Hiervoor gebruikten we een nieuw, gevalideerd instrument dat keek naar 23 aandoeningen uit 27 verschillende NHG-Standaarden. ${ }^{11}$ Mogelijke scores waren: 'niet in lijn met de richtlijn'(-1), 'discutabel' (o) en 'in lijn met de richtlijn of hier bewust van afgeweken' (1).
Daarnaast keken we naar het EBM-zoekgedrag. De deelnemende aios hielden in een logboek bij hoe vaak ze gebruikmaakten van bronnen om een klinisch dilemma uit de dagelijkse praktijk te beantwoorden. ${ }^{12}$ Klinische dilemma's waren 'alle consultgerelateerde vragen die aanleiding kunnen zijn om te zoeken naar een antwoord'. ${ }^{13}$ In het logboek werden alle face-to-face patiëntcontacten, inclusief visites maar exclusief telefonische contacten, bijgehouden en deze konden per patiënt meer dan één vraag of zoekactie bevatten. Bij de aanvangsmeting waren de logboeken op papier of digitaal, op $\mathrm{T}_{1}$ en $\mathrm{T}_{2}$ alleen digitaal.

Om de EBM-attitude te meten gebruikten we een gevalideerde vertaling van de McColl-vragenlijst, met zeven vragen. ${ }^{14-16}$

De kennis over EBM maten we met de U-CEP, een zelf ontwikkelde, gevalideerde lijst met vijftig vragen over klinische epidemiologie. ${ }^{17}$

Tot slot vroegen we alle aios en opleiders uit de interventiegroep aan het einde van de opleiding $\left(\mathrm{T}_{1}\right)$ hoe ze het geïntegreerde programma vonden en gevolgd hadden.

\section{Analyse}

De aanvangskenmerken gaven we weer als gemiddelde met standaarddeviatie (SD), mediaan met interkwartielafstand (IQR) of proportie. Het handelen volgens richtlijnen en het zoekgedrag rapporteerden we als proportie, voor de vergelijking tussen beide onderzoeksarmen berekenden we het relatieve risico (RR) met 95\%-betrouwbaarheidsinterval (95\%-BI). EBM-attitude en -kennis rapporteerden we als gemiddelde met $95 \%$-BI.

Het effect van de interventie berekenden we met behulp van meervoudige analyses, rekening houdend met mogelijke associaties tussen de uitkomsten op de verschillende meetpunten (waaronder $\mathrm{T}_{\mathrm{o}}$ ), clusterrandomisatie, type logboek (digitaal of papier) en LHK-score. ${ }^{22}$ De analyses werden uitgevoerd volgens het intention to treat-principe. Ontbrekende data imputeerden we niet.

\section{RESULTATEN}

Van de 82 aios die werden benaderd stemden er 79 (96\%) in met deelname; 39 aios werden toegewezen aan in de interventiearm en 40 aan de controlearm, Hun aanvangskenmerken en scores op de $\mathrm{T}_{\mathrm{o}}$-meting waren vergelijkbaar, behalve voor LHK-score, handelen volgens richtlijnen en zoekgedrag (zie [online tabel 2]).

Op $\mathrm{T}_{\mathrm{o}}$ hielden 76 aios ( $96 \%$ ) een logboek bij, op $\mathrm{T}_{1} 60$ (76\%) en op $\mathrm{T}_{2} 53(67 \%)$. De logboeken hadden betrekking op in totaal 15.894 consulten (gemiddeld 72 per aios, SD 33, uitersten 6 tot 169), waarvan 7614 (48\%) op $\mathrm{T}_{\mathrm{o}}$, 4973 (31\%) op $\mathrm{T}_{1}$ en 3307 (21\%) op $\mathrm{T}_{2}$. In totaal $81 \%$ van de logboeken werd digitaal bijgehouden, met op $\mathrm{T}_{\mathrm{o}}$ een significant verschil tussen de interventiegroep (16\% digitaal) en de controlegroep (79\% digitaal, $\mathrm{p}<0,05)$.

Op $\mathrm{T}_{\mathrm{o}}$ vulden 79 aios (100\%) de vragenlijsten over EBM-attitude en -kennis in, op $\mathrm{T}_{1} 66$ (84\%) en op $\mathrm{T}_{2} 58$ (73\%).

In de interventiearm was meer loss to follow-up dan in de 
controlearm (41 versus $25 \%$ voor logboeken, 33 vs. $20 \%$ voor vragenlijsten).

Bij de metingen aan het einde van de opleiding $\left(T_{1}\right)$ en een jaar daarna $\left(T_{2}\right)$ vonden we geen significante verschillen tussen de interventie- en de controlearm op het gebied van zoekgedrag, handelen volgens richtlijnen, EBM-attitude en EBM-kennis.

Aan het einde van de opleiding $\left(\mathrm{T}_{1}\right)$ gaven 17 aios uit de interventiearm (44\%) feedback over het onderwijsprogramma. Zestien van hen (94\%) hadden EBM-leergesprekken met hun opleider gehad, $2(12 \%)$ zelfs wekelijks. Iets meer dan de helft (53\%) had nauwelijks artikelen besproken, $29 \%$ had dat minder dan eenmaal in de twee maanden gedaan. Ze waardeerden het EBM-onderwijsprogramma met gemiddeld een 6 op een schaal van 1 tot 10.

\section{BESCHOUWINC}

\section{Sterke punten en beperkingen}

Ons onderzoek was het eerste gerandomiseerde gecontroleerde onderzoek waarin is gekeken of geïntegreerd EBMonderwijs in het laatste jaar van de huisartsopleiding leidt tot verbetering in kennis, attitude en gedrag ten opzichte van gangbare, losse onderwijsmodules. Een ander sterk punt is dat we dit hebben onderzocht tot een jaar na het afstuderen.

Vergeleken met het gangbare onderricht leidde het geïntegreerde EBM-onderwijsprogramma dat we ontwikkelden niet tot betere EBM-kennis, -attitude en -gedrag. We kunnen daar wel een paar kanttekeningen bij plaatsen. Misschien gebruikten we niet de juiste meetinstrumenten - er is discussie over de juiste manier om EBM-kennis en -gedrag in kaart te brengen, de uitersten in onze uitkomsten lagen ook ver uiteen..$^{30}$ Daarbij scoorden onze aios al bij de start van het onderzoek goed op een aantal vaardigheden, zodat er relatief weinig ruimte was voor verbetering. Tot slot was de uitvoering van onze interventie niet altijd optimaal, waardoor het geïntegreerde onderwijs misschien onvoldoende contrasteerde met het gangbare programma, dat per slot ook met praktijkvoorbeelden werkt.

De verdere inbedding van het geïntegreerde EBM-programma in de praktijk viel uiteindelijk tegen. Daarvoor waren we grotendeels afhankelijk van de aios en opleiders, want we wilden bewust niet te veel interveniëren omdat onze resultaten anders niet representatief zouden zijn voor de situatie buiten onderzoeksverband. Het gevolg was dat er grote verschillen waren in de implementatie van de verschillende onderwijsonderdelen. We hebben aios en opleiders zo nauw mogelijk betrokken bij het onderzoek en ook de EBMattitude expliciet aan de orde gesteld, maar toch hebben we onderschat hoeveel weerstand er nog altijd was. Dat was niet alleen weerstand tegen deelname aan het onderzoek, maar ook een basale, deels onbewuste weerstand tegen het begrip EBM. ${ }^{16,31}$

\section{Betekenis voor de praktijk}

Nog steeds denken veel huisartsen dat EBM alleen gaat over wetenschappelijk onderzoek en interpretatie van literatuur, terwijl het juist draait om de integratie daarvan met de eigen klinische expertise en met de wensen en voorkeuren van de patiënt. ${ }^{32}$ Juist in een tijd waarin arts en patiënt beschikken over een overvloed aan informatie. moeten ze die op waarde kunnen schatten, ook om zo nodig weloverwogen en expliciet te kunnen afwijken van een aanbeveling. Niet voor niets zijn in een recent overzichtsartikel de volgende drie samenhangende competenties voor de huisarts geformuleerd in de huidige, hectische praktijk: een bewuste, reflectieve benadering van EBM en alle factoren die onze besluitvorming beïnvloeden, pragmatisch zoeken en evalueren van evidence, en kennis van de patiënt. ${ }^{33}$

We deden dit onderzoek om meer zicht te krijgen op de beste manier om EBM-gedrag aan te leren. Huisartsen zijn voldoende competent als het gaat om klinische expertise en rekening houden met de patiënt, maar in de praktijk schort het vaak aan de juiste attitude en kennis om daarbij ook evidence-based te handelen. ${ }^{16}$ Dat zagen we terug in ons onderzoek.

We zouden de lezer graag een spiegel voorhouden: hoe staat het met je eigen EBM-gedrag, attitude en kennis? Natuurlijk gebruik je vaak de NHG-Standaarden en betrek je daarbij je eigen expertise en de wensen van je patiënt. Maar weet je bijvoorbeeld ook waarop de aanbevelingen in de NHGStandaard gebaseerd zijn en wanneer je ervan zou moeten afwijken? Hoe weeg je de evidence af tegen je eigen expertise en de wensen van je patiënt? Wat doe je als de standaard geen antwoord geeft? Hoe vaak heb je een klinisch dilemma tijdens het spreekuur en wat doe je dan? Hoe bespreek je de evidence en je afwegingen met collega's? Ben je in staat pragmatisch naar nieuwe en bestaande evidence te zoeken en die te beoordelen en toe te passen bij, of aan te passen aan, de patiënt die voor je in de spreekkamer zit? Als we dat doen, doen we uiteindelijk nog beter waar huisartsen goed in zijn; kwalitatief goede zorg leveren waarin de patiënt centraal staat.

\section{DANKBETUIGING}

De onderzoekers Yvonne Spoormans, Lisanne Welink en Jeroen van Duijn analyseerden de consultdata omtrent het volgen van richtlijnen.

\section{LITERATUUR}

1 Sackett DL, Rosenberg WMC, Gray J a M, Haynes RB, Richardson WS. Evidence based medicine: what it is and what it isn't. 1996. BMJ 1996;312:71-2.

2 Frank JR. The CanMEDS 2005 physician competency framework: Better standards, better physicians, better care. Ottawa: The Royal College of Physicians and Surgeons of Canada: 2005.

3 Dawes M, Summerskill W, Glasziou P, Cartabellotta A, Martin J, Hopayian $\mathrm{K}$, et al. Sicily statement on evidence-based practice. BMC Med Educ 2005;5:1.

De rest van de literatuur staat bij dit artikel op www.henw.org. 


\section{LITERATUUR}

1 Kortekaas MF, Bartelink MEL. Evidence-based medicine, meer dan evidence alleen. Huisarts Wet 2017;60(9):450.

2 Kortekaas MF. Improving evidence-based general practice [proefschrift]. Utrecht: Universiteit Utrecht, 2016.

3 Te Pas E. Blended learning in continuing professional development: Studies on a blended learning intervention on EBM for GP-trainers [dissertation]. Amsterdam: Universiteit van Amsterdam, 2015.

4 Ilic D, Maloney S. Methods of teaching medical trainees evidence-based medicine: A systematic review. Med Educ 2014:48:124-35.

5 Coomarasamy A, Khan KS. What is the evidence that postgraduate teaching in evidence based medicine changes anything? A systematic review. BMJ 2004;329:1017.

6 Taylor R, Reeves B, Ewings P, Binns S, Keast J, Mears R. A systematic review of the effectiveness of critical appraisal skills training for clinicians. Med Educ 2000;34:120-5.

7 Van Dijk N, Hooft L, Wieringa-de Waard M. What are the barriers to residents' practicing evidence-based medicine? A systematic review. Acad Med 2010;85:1163-70.

8 Van Leeuwen YD, Pollemans MC, Mol SS, Eekhof JA, et al. The Dutch knowledge test for general practice: issues of validity. Eur J Gen Pract 1995;1:113 7.

9 Grobbee D, Hoes A. Clinical epidemiology: Principles, methods and applications for clinical research. 1st ed. London: Jones and Bartlett, 2009.

10 Offringa WJJ, Assendelft RJPMS. Inleiding evidence-based medicine: Klinisch handelen gebaseerd op bewijsmateriaal. Houten: Bohn Stafleu van Loghum, 2008.

11 Kortekaas MF, Bartelink ML, Van der Heijden GJ, Hoes AW, de Wit NJ. Development and validation of a new instrument measuring guideline adherence in clinical practice. Fam Pract 2016:33:562-8.

12 Ely JW, Osheroff JA, Chambliss ML, Ebell MH, Rosenbaum ME. Answering physicians' clinical questions: obstacles and potential solutions. J Am Med Inform Assoc 2005;12:217-24.

13 Kortekaas MF, Bartelink ML, Boelman L, Hoes AW, de Wit NJ. Genera practice trainees' information searching strategies for clinical queries encountered in daily practice. Fam Pract 2015;32:533-7.

14 McColl A, Smith H, White P, Field J. General practitioner's perceptions of the route to evidence based medicine: a questionnaire survey. BMJ 1998;316:361-5.

15 Knops AM, Vermeulen H, Legemate DA, Ubbink DT. Attitudes, awareness, and barriers regarding evidence-based surgery among surgeons and surgical nurses. World J Surg 2009;33:1348-55.

16 Te Pas E, van Dijk N, Bartelink ME, Wieringa-De Waard M. Factors influencing the EBM behaviour of GP trainers: a mixed method study. Med Teach 2013;35:e990-7.
17 Kortekaas MF, Bartelink MEL, de Groot E, Korving H, de Wit NJ, Grobbee DECD, Hoes AW. The Utrecht questionnaire (U-CEP) measuring knowledge on clinical epidemiology proved to be valid. J Clin Epidemiol 2017;82:11927.

18 Khan KS, Dwarakanath LS, Pakkal M, Brace V, Awonuga A. Postgraduate journal club as a means of promoting evidence-based obstetrics and gynaecology. J Obstet Gynaecol 1999;19:231-4.

19 Magrabi F, Coiera EW, Westbrook JI, Gosling a S, Vickland V. General prac titioners' use of online evidence during consultations. Int J Med Inform 2005;74:1-12.

20 Van Duppen D, Aertgeerts B, Hannes K, Neirinckx J, Seuntjens L, Goossens $\mathrm{F}$, et al. Online on-the-spot searching increases use of evidence during consultations in family practice. Patient Educ Couns 2007;68:61-5.

21 Epicalc [internet]. www.brixtonhealth.com/epicalc.html.

22 Zeger SL, Liang KY, Albert PS. Models for longitudinal data: A generalized estimating equation approach. Biometrics 1988;44:1049-60.

23 Davies K, Harrison J. The information-seeking behaviour of doctors: a review of the evidence. Health Info Libr J 2007;24:78-94.

24 Green ML, Ciampi Ma, Ellis PJ. Residents' medical information needs in clinic: are they being met? Am J Med 2000;109:218-23.

25 Allan GM, Ma V, Aaron S, Vandermeer B, Manca D, Korownyk C. Residents' clinical questions: how are they answered and are the answers helpful? Can Fam Physician 2012;58:e344-51.

26 McCord G, Smucker WD, Selius BA, Hannan S, Davidson E, Schrop SL, et al. Answering questions at the point of care: do residents practice EBM or manage information sources? Acad Med 2007:82:298-303.

27 Kortekaas M, Meijer A, ven de Pol AC, de Wit N. RCT's in de huisartsgenees kunde, 1990-2010. Huisarts Wet 2012;55:486-91.

28 Glanville J, Kendrick T, McNally R, Campbell J, Hobbs FD. Research output on primary care in Australia, Canada, Germany, the Netherlands, the United Kingdom, and the United States: bibliometric analysis. BM] 2011;342:d1028

29 Schaafsma F, Verbeek J, Hulshof C, van Dijk F. Caution required when relying on a colleague's advice; a comparison between professional advice and evidence from the literature. BMC Health Serv Res 2005;5:59.

30 Oude Rengerink K, Zwolsman SE, Ubbink DT, Mol BWJ, Van Dijk N, Vermeulen $\mathrm{H}$. Tools to assess evidence-based practice behaviour among healthcare professionals. Evid Based Med 2013;18:129-38.

31 Van Dijk N, Hooft L, Wieringa-de Waard M. What are the barriers to resi dents' practicing evidence-based medicine? A systematic review. Acad Med 2010;85:1163-70.

32 Greenhalgh T, Howick J, Maskrey N; Evidence Based Medicine Renaissance Group. Evidence based medicine: a movement in crisis? BM 2014;348:g3725.

33 Galbraith K, Ward A, Heneghan C. A real-world approach to evidencebased medicine in general practice: a competency framework derived from a systematic review and Delphi process. BMC Med Educ 2017;17:78. 
Tabel 1 Een in de praktijk geïntegreerd onderwijsprogramma voor evidence-based medicine (EBM) vergeleken met onderwijs via losse theoretische modules

\begin{tabular}{|c|c|c|}
\hline Setting & Interventie: geïntegreerd EBM-programma & Controle: losse EBM-modules \\
\hline \multirow[t]{3}{*}{ Praktijk* } & Dagelijks leergesprek van 1 uur met de opleider & Dagelijks leergesprek van 1 uur met de opleider; EBM is geen expliciet onderwerp \\
\hline & $\begin{array}{l}\text { Eens per week een EBM-leergesprek waarbij evidence expliciet aan de orde } \\
\text { komt en de klinische expertise van de opleider gecombineerd wordt met de } \\
\text { EBM-vaardigheden van de aios }\end{array}$ & \\
\hline & $\begin{array}{l}\text { Eens per maand samen met de opleider een artikel kritisch lezen; de aios } \\
\text { ontvangt een e-mail met suggesties en wordt aangemoedigd andere klinisch } \\
\text { relevante artikelen te besprekent }\end{array}$ & Geen opdracht om samen met de opleider een artikel te lezen \\
\hline \multirow[t]{5}{*}{ Opleiding* } & $\begin{array}{l}\text { Vijf dagen per jaar een EBM-cursus van 2,5 uur waarin de nadruk ligt op } \\
\text { toepassen en evalueren (de laatste twee stappen van EBM) }\end{array}$ & $\begin{array}{l}\text { Vier dagen per jaar een EBM-cursus van 2,5 uur waarin de nadruk ligt op vragen, } \\
\text { zoeken, en kritisch beoordelen (de eerste drie stappen van EBM) }\end{array}$ \\
\hline & Patiëntgerelateerde opdrachten, samen met de opleider uit te voeren & Opdrachten over fictieve patiënten \\
\hline & $\begin{array}{l}\text { Eén uur per week uitwisseling van ervaringen uit de praktijk, waarvan } 15 \\
\text { minuten voorbereid door de aios over een casus waarbij gezocht is naar } \\
\text { evidence }\end{array}$ & $\begin{array}{l}\text { Eén uur per week uitwisseling van ervaringen uit de praktijk; EBM komt bniet } \\
\text { expliciet aan de orde }\end{array}$ \\
\hline & $\begin{array}{l}\text { Aan het begin van het jaar een coachingsessie over de EBM-attitude, waarin we } \\
\text { de aios vroegen te discussiëren over hun EBM-behoeften en -barrières zodat } \\
\text { we het programma daaraan konden aanpassen }\end{array}$ & - \\
\hline & Presentatie van een critically appraised topic (CAT) & - \\
\hline \multirow[t]{2}{*}{ Online } & Mogelijkheden voor uitgebreide e-learning geïntegreerd in het programma & Mogelijkheid om e-learning te volgen \\
\hline & Online coaching mogelijk & - \\
\hline \multirow[t]{2}{*}{ Extra } & Mogelijkheid tot deelname aan klinisch onderzoek & Mogelijkheid tot deelname aan klinisch onderzoek \\
\hline & Extra EBM-cursus mogelijk & Extra EBM-cursus mogelijk \\
\hline \multirow[t]{3}{*}{ Opleiders } & $\begin{array}{l}\text { Tweemaal per jaar een dag EBM-onderwijs op het opleidingsinstituut, met } \\
\text { sessies over hoe EBM geïntegreerd kan worden in de dagelijkse praktijk en } \\
\text { leergesprekken over het belang van de functie als rolmodel voor EBM }\end{array}$ & - \\
\hline & Viermaal per jaar een uur EBM-onderwijs op het opleidingsinstituut & - \\
\hline & $\begin{array}{l}\text { Praktijkopdrachten bij de zes cursusdagen die vooraf en achteraf samen met de } \\
\text { aios uitgevoerd moeten worden }\end{array}$ & - \\
\hline
\end{tabular}

Bronnen: Hoes 2009, ${ }^{9}$ Offringa 2008. ${ }^{10}$

* Bij een volledige werkweek waren de aios vier dagen werkzaam op de praktijk en één dag op de huisartsopleiding.

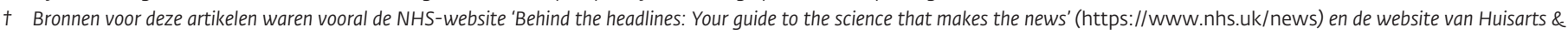
Wetenschap (https://www.henw.org). 
Tabel 2 Evidence-based handelen door derdejaars aios Huisartsgeneeskunde in 2011

\begin{tabular}{|c|c|c|c|c|c|c|c|c|c|}
\hline & \multicolumn{3}{|l|}{$T_{0}(n=76)$} & \multicolumn{3}{|l|}{$T_{1}(n=60)$} & \multicolumn{3}{|l|}{$T_{2}(n=53)$} \\
\hline & $\begin{array}{l}\text { interventie } \\
(n=38)\end{array}$ & $\begin{array}{l}\text { controle } \\
(n=38)\end{array}$ & RR & $\begin{array}{l}\text { interventie } \\
(n=29\end{array}$ & $\begin{array}{l}\text { controle } \\
(n=31)\end{array}$ & RR & $\begin{array}{l}\text { interventie } \\
(n=23\end{array}$ & $\begin{array}{l}\text { controle } \\
(n=30)\end{array}$ & RR \\
\hline \multicolumn{10}{|l|}{ Zoekgedrag } \\
\hline $\begin{array}{l}\text { Aantal klinische dilemma's } \\
\text { per patiënt }\end{array}$ & $\begin{array}{l}0,25 \\
(0,21 \text { tot } 0,29)\end{array}$ & $\begin{array}{l}0,17 \\
(0,15 \text { tot } 0,20)\end{array}$ & $\begin{array}{l}1,45 \\
(1,15 \text { tot } 1,83)\end{array}$ & $\begin{array}{l}0,14 \\
(0,13 \text { tot } 0,16)\end{array}$ & $\begin{array}{l}0,15 \\
(0,13 \text { tot } 0,17)\end{array}$ & $\begin{array}{l}0,95 \\
(0,80 \text { tot } 1,12)\end{array}$ & $\begin{array}{l}0,21 \\
(0,19 \text { tot } 0,23)\end{array}$ & $\begin{array}{l}0,19 \\
(0,16 \text { tot } 0,22)\end{array}$ & $\begin{array}{l}1,10 \\
(0,92 \text { tot } 1,32)\end{array}$ \\
\hline Zoekacties per klinisch dilemma & $\begin{array}{l}0,77 \\
(0,72 \text { tot } 0,82)\end{array}$ & $\begin{array}{l}0,82 \\
(0,75 \text { tot } 0,91)\end{array}$ & $\begin{array}{l}0,93 \\
(0,83 \text { tot } 1,05)\end{array}$ & $\begin{array}{l}0,71 \\
(0,64 \text { tot } 0,79)\end{array}$ & $\begin{array}{l}0,72 \\
(0,68 \text { tot } 0,76)\end{array}$ & $\begin{array}{l}0,98 \\
(0,87 \text { tot } 1,11)\end{array}$ & $\begin{array}{l}0,60 \\
(0,59 \text { tot } 0,61)\end{array}$ & $\begin{array}{l}0,67 \\
(0,57 \text { tot } 0,79)\end{array}$ & $\begin{array}{l}0,90 \\
(0,76 \text { tot } 1,07)\end{array}$ \\
\hline $\begin{array}{l}\text { Zoekacties per klinisch dilemma } \\
\text { in EBM-bronnen" }\end{array}$ & $\begin{array}{l}0,32 \\
(0,26 \text { tot } 0,38)\end{array}$ & $\begin{array}{l}0,30 \\
(0,24 \text { tot } 0,39)\end{array}$ & $\begin{array}{l}1,05 \\
(0,77 \text { tot } 1,44)\end{array}$ & $\begin{array}{l}0,27 \\
(0,21 \text { tot } 0,35)\end{array}$ & $\begin{array}{l}0,24 \\
(0,15 \text { tot } 0,38)\end{array}$ & $\begin{array}{l}1,16 \\
(0,70 \text { tot } 1,91)\end{array}$ & $\begin{array}{l}0,27 \\
(0,24 \text { tot } 0,30)\end{array}$ & $\begin{array}{l}0,30 \\
(0,23 \text { tot } 0,38)\end{array}$ & $\begin{array}{l}0,90 \\
(0,70 \text { tot } 1,16)\end{array}$ \\
\hline $\begin{array}{l}\text { Gevonden antwoorden } \\
\text { per zoekactie }\end{array}$ & $\begin{array}{l}0,84 \\
(0,81 \text { tot } 0,88)\end{array}$ & $\begin{array}{l}0,81 \\
(0,77 \text { tot } 0,85)\end{array}$ & $\begin{array}{l}1,04 \\
(0,98 \text { tot } 1,11)\end{array}$ & $\begin{array}{l}0,81 \\
(0,72 \text { tot } 0,90)\end{array}$ & $\begin{array}{l}0,79 \\
(0,72 \text { tot } 0,85)\end{array}$ & $\begin{array}{l}1,03 \\
(0,97 \text { tot } 1,10)\end{array}$ & $\begin{array}{l}0,82 \\
(0,78 \text { tot } 0,86)\end{array}$ & $\begin{array}{l}0,78 \\
(0,71 \text { tot } 0,85)\end{array}$ & $\begin{array}{l}1,05 \\
(0,98 \text { tot } 1,13)\end{array}$ \\
\hline $\begin{array}{l}\text { Gevonden antwoorden per } \\
\text { zoekactie in EBM-bronnen }\end{array}$ & $\begin{array}{l}0,91 \\
(0,87 \text { tot } 0,96)\end{array}$ & $\begin{array}{l}0,88 \\
(0,84 \text { tot } 0,93)\end{array}$ & $\begin{array}{l}1,03 \\
(0,97 \text { tot } 1,10)\end{array}$ & $\begin{array}{l}0,87 \\
(0,83 \text { tot } 0,91)\end{array}$ & $\begin{array}{l}0,90 \\
(0,82 \text { tot } 0,99)\end{array}$ & $\begin{array}{l}0,97 \\
(0,87 \text { tot } 1,07)\end{array}$ & $\begin{array}{l}0,86 \\
(0,81 \text { tot } 0,92)\end{array}$ & $\begin{array}{l}0,96 \\
(0,89 \text { tot } 1,03)\end{array}$ & $\begin{array}{l}0,90 \\
(0,79 \text { tot } 1,03)\end{array}$ \\
\hline \multicolumn{10}{|l|}{ Handelen volgens richtlijnen } \\
\hline $\begin{array}{l}\text { Alle onderdelen binnen } \\
\text { een consult }\end{array}$ & $\begin{array}{l}0,47 \\
(0,42 \text { tot } 0,53)\end{array}$ & $\begin{array}{l}0,68 \\
(0,62 \text { tot } 0,74)\end{array}$ & $\begin{array}{l}0,69 \\
(0,60 \text { tot } 0,80)\end{array}$ & $\begin{array}{l}0,62 \\
(0,59 \text { tot } 0,66)\end{array}$ & $\begin{array}{l}0,64 \\
(0,60 \text { tot } 0,70)\end{array}$ & $\begin{array}{l}0,96 \\
(0,86 \text { tot } 1,08)\end{array}$ & $\begin{array}{l}0,67 \\
(0,60 \text { tot } 0,74)\end{array}$ & $\begin{array}{l}0,60 \\
(0,56 \text { tot } 0,65)\end{array}$ & $\begin{array}{l}1,10 \\
(0,97 \text { tot } 1,25)\end{array}$ \\
\hline Totaal aantal keren & $\begin{array}{l}0,69 \\
(0,65 \text { tot } 0,73)\end{array}$ & $\begin{array}{l}0,85 \\
(0,82 \text { tot } 0,88)\end{array}$ & $\begin{array}{l}0,81 \\
(0,76 \text { tot } 0,86)\end{array}$ & $\begin{array}{l}0,83 \\
(0,81 \text { tot } 0,84)\end{array}$ & $\begin{array}{l}0,83 \\
(0,82 \text { tot } 0,85)\end{array}$ & $\begin{array}{l}0,99 \\
(0,97 \text { tot } 1,02)\end{array}$ & $\begin{array}{l}0,83 \\
(0,80 \text { tot } 0,87)\end{array}$ & $\begin{array}{l}0,80 \\
(0,78 \text { tot } 0,83)\end{array}$ & $\begin{array}{l}1,04 \\
(0,98 \text { tot } 1,10)\end{array}$ \\
\hline Diagnostische beslissingen & $\begin{array}{l}0,66 \\
(0,63 \text { tot } 0,68)\end{array}$ & $\begin{array}{l}0,88 \\
(0,86 \text { tot } 0,91)\end{array}$ & $\begin{array}{l}0,74 \\
(0,71 \text { tot } 0,78)\end{array}$ & $\begin{array}{l}0,87 \\
(0,85 \text { tot } 0,90)\end{array}$ & $\begin{array}{l}0,88 \\
(0,87 \text { tot } 0,89)\end{array}$ & $\begin{array}{l}0,99 \\
(0,96 \text { tot } 1,02)\end{array}$ & $\begin{array}{l}0,85 \\
(0,84 \text { tot } 0,87)\end{array}$ & $\begin{array}{l}0,83 \\
(0,79 \text { tot } 0,87)\end{array}$ & $\begin{array}{l}1,03 \\
(0,98 \text { tot } 1,09)\end{array}$ \\
\hline Therapeutische beslissingen & $\begin{array}{l}0,58 \\
(0,51 \text { tot } 0,65)\end{array}$ & $\begin{array}{l}0,71 \\
(0,65 \text { tot } 0,78)\end{array}$ & $\begin{array}{l}0,81 \\
(0,69 \text { tot } 0,94)\end{array}$ & $\begin{array}{l}0,66 \\
(0,62 \text { tot } 0,69)\end{array}$ & $\begin{array}{l}0,66 \\
(0,61 \text { tot } 0,72)\end{array}$ & $\begin{array}{l}0,99 \\
(0,89 \text { tot } 1,11)\end{array}$ & $\begin{array}{l}0,72 \\
(0,68 \text { tot } 0,76)\end{array}$ & $\begin{array}{l}0,66 \\
(0,60 \text { tot } 0,73)\end{array}$ & $\begin{array}{l}1,09 \\
(0,97 \text { tot } 1,23)\end{array}$ \\
\hline Met betrekking tot verwijzing & $\begin{array}{l}0,81 \\
(0,79 \text { tot } 0,84)\end{array}$ & $\begin{array}{l}0,94 \\
(0,93 \text { tot } 0,96)\end{array}$ & $\begin{array}{l}0,86 \\
(0,83 \text { tot } 0,89)\end{array}$ & $\begin{array}{l}0,93 \\
(0,92 \text { tot } 0,95)\end{array}$ & $\begin{array}{l}0,95 \\
(0,94 \text { tot } 0,96)\end{array}$ & $\begin{array}{l}0,98 \\
(0,96 \text { tot } 1,00)\end{array}$ & $\begin{array}{l}0,91 \\
(0,86 \text { tot } 0,97)\end{array}$ & $\begin{array}{l}0,92 \\
(0,89 \text { tot } 0,94)\end{array}$ & $\begin{array}{l}0,99 \\
(0,92 \text { tot } 1,07)\end{array}$ \\
\hline
\end{tabular}

De cijfers betreffen zelfgerapporteerd zoekgedrag in logboeken en zijn weergegeven als proportie met $95 \%$-betrouwbaarheidsinterval. De cijfers voor het zoekgedrag bij de aanvangsmeting $\left(T_{0}\right)$ zijn gebaseerd op de ruwe gegevens; de metingen van het handelen volgens richtlijnen zijn gecorrigeerd voor type logboek (papier of digitaal) en score op de Landelijke Huisartsgeneeskundige Kennistoets. De metingen aan het eind van het derde studiejaar $\left(T_{1}\right)$ en één jaar na afstuderen $\left(T_{2}\right)$ zijn gecorrigeerd voor herhaalde meting.

"EBM = evidence-based medicine; de bronnen zijn richtlijnen, reviews en primaire bibliografische databases zoals Clinical Evidence, Cochrane en PubMed. 